\title{
Selection and Propagation of Antibiotic-resistant Mutants of Acholeplasma by the Addition of Fresh Culture Medium Containing Antibiotics and Protease to the Medium Cultured with Acholeplasma
}

\author{
RYUICHI HASHIMOTO AND MASAHIRO NAKAMURA \\ Department of Microbiology, Kurume University School of Medicine, \\ Kurume, 830 Japan
}

Received for publication January 12, 1985

\begin{abstract}
Summary: A simple procedure for obtainig drug-resistant strains of Acholeplasma, occuring naturally and spontaneously at a low frequency in a broth culture was described. The drug-resistant strains could be obtained and enriched for by the addition of more than twice volumes of fresh broth containing antibiotics to a pre-cultured medium with Acholeplasma at the plateau phase of the growth. Furthermore, the growth of drug-resistant cells was promoted by the addition of broth containing protease and an antibiotics. By means of this procedure, various kinds of antibiotics-resistant strains of Acholeplasma were easily isolated, some of which were not obtained by the agar plate selection method. The merits of this procedure were that the scale of this system could be controlled and that the isolation of drug-resistant strain was very simple and rapid.
\end{abstract}

Key words: drug-resistant mutants - acholeplasma - selection - enrich ment - SE-broth

\section{Introduction}

Due to their genetic simplicity, mycoplasma have been considered to be a useful models for genetic research (Amikan et al. 1982). However, due to this simplicity, very few differential biological markers are available in these organisms. Presently, drug-resistance is the only useful marker for genetic research in mycoplasma. Therefore, establishment of a method for selection and enrichment of drug-resistant mutants from parent strains of mycoplasma is essential.

One method which has been used for selection of drug resistant mutants of mycoplasma is tha agar plate selection technique. Koostra et al. (1966) reported a method for selection of drug-resistant mu- tants of mycoplasma with an agar plate containing antibiotics, in which hemolytic activity was used for locating small resistant colonies. However, it would be difficult to select a mutant by this method in the case of an extremely low mutational frequency, because of the limitation in inoculum size. In addition, this method required hemolytic activity for the marker. A similar disadvantage is found in the method of Szybalski (1952), which was used for the selection of mutants of E. coli.

Alternatively, selection by subcultivation of microorganisms in a culture medium containing serial diluted drug is tedious and ineffecient. In order to improve on the methods previously reported, we developed a method for selection and enrichment of drug-resistant mutants of Achole- 
plasmas in which fresh culture medium containing antibiotics and protease was added to the medium cultured with Acholeplasma.

\section{Materials and Methods}

\section{Organisms used}

A. laidlawii A, catalog number M 728001, which was kindly supplied by Dr. M. F. Barile, Bureau of Biologics, U.S. Food and Drug Administration, has been maintained in PPLO-broth in our laboratory. This strain is sensitive to $0.05 \mathrm{mcg} / \mathrm{ml}$ of erythromycin (EM).

A. axanthum $\mathrm{S} 743$ was kindly supplied by Dr. J.G. Tully, National Institute of Health, U.S. A., through Dr. Koshimizu, University of Tokyo and also has been maintained in PPLO-broth at our laboratory.

\section{Culture medium}

For multiplication of acholeplasmal cells, PPLO-broth (Difco) supplimented $10 \%$ yeast extract was used.

Selection and enrichment of drug resistant mutants

Maximum growth of acholeplasmal cells was obtained by cultivation at $37^{\circ} \mathrm{C}$ for 2 or 3 days. At that time, fresh PPLO-broth containing various drugs was added to the cultured medium. This mixed medium was further incubated aerobically at $37^{\circ} \mathrm{C}$ for a period of time determined by the growth rates of resistant mutant cells. The medium containing drug previously described is tentatively refferred to as SE-broth (Selection and enrichment broth).

\section{Titer of resistant cells}

For this, PPLO-agar containing drug was used. The concentration of drug was the same as that of the mixed medium mentioned above. The number of resistant acholeplasmal cells was determined by the method of Smith (1956).

\section{Enzymes}

Protease type XIV and trypsin were purchased from Sigma Co. Ltd.

\section{Results}

Effect of addition of culture medium containing EM on the enrichment of EM resistant mutants of $A$. laidlawii

Growth of erythromycin (EM)-resistant mutant cells was markedly stimulated by the addition of SE-broth to the medium. No such multiplication of resistant cells was observed when only fresh broth without : $\mathrm{EM}$ or $20 \mathrm{mcg} / \mathrm{ml}$ of $\mathrm{EM}$ (final concentration) were added to the culture medium. Following the addition of SE-broth, A. laidlawii cells resistant to EM grew slowly and reached approximately $7.0 \mathrm{log}$ $\mathrm{cfu} / \mathrm{ml}$ after eleventh days of cultivation. No significant difference between yields of EM-resistant cells at EM concentrations of 20 to $200 \mathrm{mcg} / \mathrm{ml}$ was observed.

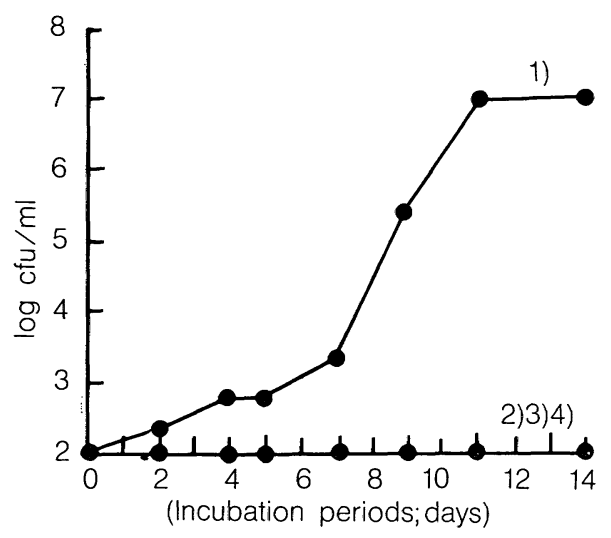

Fig. 1. Effect of the addition of fresh PPLO broth containing EM on the growth of EM resistant A. laidlawii A

1) Addition of PPLO broth containing EM

2) Addition of PPLO broth

3) Addition of EM

4) No addition 
Relationship between fresh SE-broth volume and growth of EM-resistant cells.

In order to obtain abundant growth of EM-resistant cells of $A$. laidlawii, the effect of volume of SE-broth to be added was tested. The rate of increase of resistant cells paralleled the increase in volume of SE-broth added (Fig. 2). An increase in resistant cells was observed when either twice or thrice volumes of SE-broth was added to the original culture medium. Growth of resistant cells was observed earlier with addition of thrice volumes than with that of twice volumes. No resistant cells were obtained when an equal volume of SE-broth was added to the culture meium.

Detection of a growth inhibitory substance released from killed, EM-sensitive acholeplasmal cells

The previous experiment, demonstrated that the addition of an equal volume of SEbroth to cultured medium failed to support the growth of resistant cells. Presumably, it might be possible that a growth inhibitory substance was released from killed EM-sensitive cells. Therefore, the following experiment was carried out. An equal volume of SE-broth was added to the cultured medium with A. laidlawii. After 3 days of cultivation, a cell-free filtrate was prepared. EM-resistant Acholeplasma cells inoculated into this filtrate were slowly inactivated (curve 1). Conversely, if the filtrate was first heated at $70^{\circ} \mathrm{C}$ for $30 \mathrm{~min}$., this inhibitory activity was lost (curve 2). Further studies revealed that the inhibitory activity could be abolised by the addition of $10 \mathrm{mcg} / \mathrm{ml}$ protease or trypsin. These treatments had no direct effect on resistant cells.

Effect of SE-broth on the yield of EM-resistant $A$. axanthum

As described above, a simple procedure for obtaining drug resistant mutants of

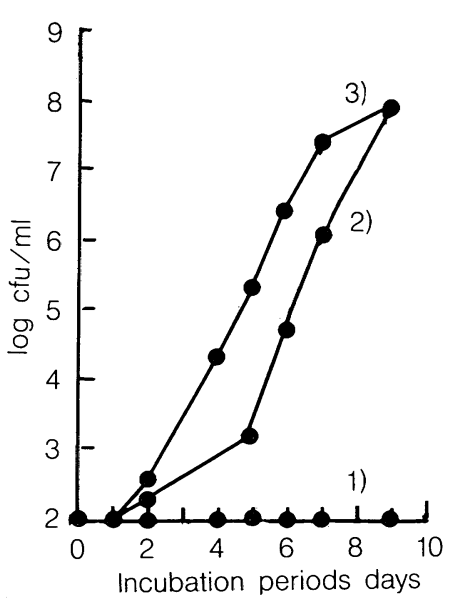

Fig. 2. Effect of the volume of fresh broth containing EM on the growth of EM resistant $A$. laidlawii A

1) Addition of equal volume of EM-broth

2) Addition of twice volumes of EM-broth

3) Addition of thrice volumes of EM-broth

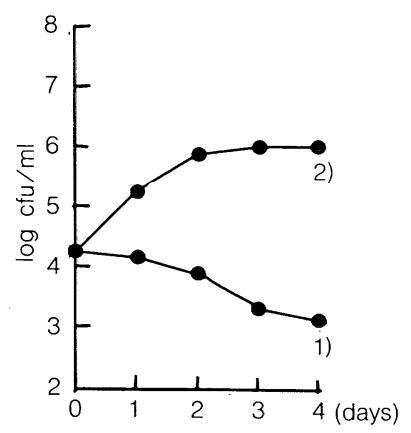

Fig. 3. Growth of A. laidlawii $\mathrm{A} \mathrm{EM}^{\mathrm{R}}$ in culture filtrate of $A$. laidlawii $\mathrm{A} \mathrm{EM}^{\mathrm{s}}$ containing EM

1) not heated culture filtrate

2) heated culture filtrate

A. laidlawii was established here. Subsequently, an attempt to select an EM-resistant strain of $A$. axanthum on an agar plate was unsuccessful. The method for isolation of resistant cells by using SEbroth was applied to this strain. $90 \mathrm{ml}$ of SE-broth was added to $30 \mathrm{ml}$ of cultured medium with $A$. axanthum. No resistant 
cells were detected at zero time, but after 5 days of cultivation, approximately 8.0 $\log \mathrm{cfu} / \mathrm{ml}$ of EM-resistant cells of $A$. axanthum was obtained (Fig. 5).

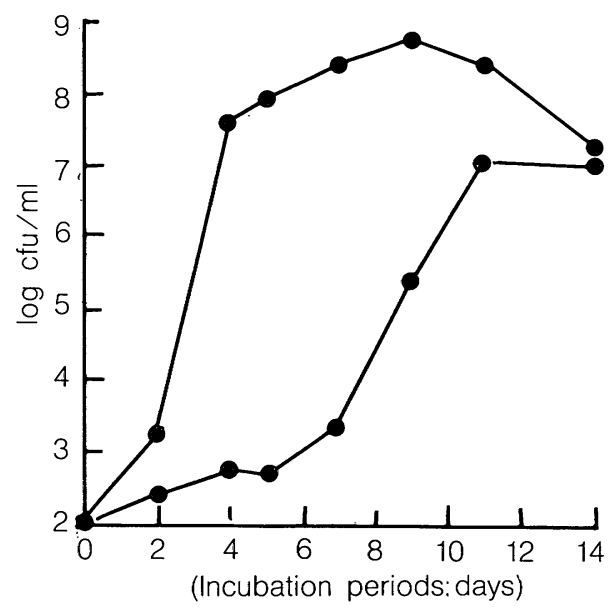

Fig. 4. Effect of the addition of fresh PPLO broth containing EM and protease on the growth of EM resistant $A$. laidlawii A Addition of PPLO broth containing EM Addition of PPLO broth with EM and protease

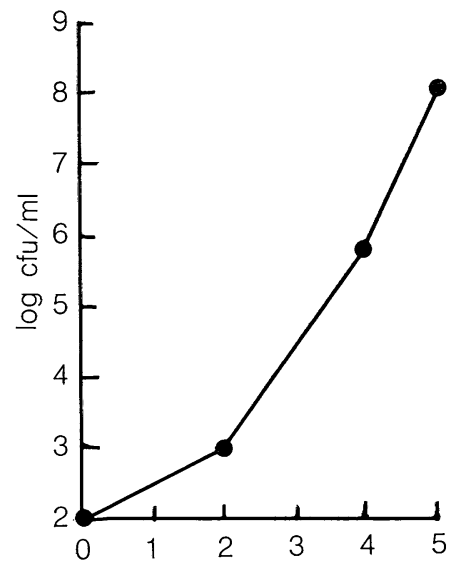

Fig. 5. Effect of the addition of fresh PPLO broth containing EM on the growth of EM resistant $A$. axanthum

\section{Discussion}

The biological markers which differentiate one strain from another are extremely limited in mycoplasma. This makes genetic research difficult in the field of mycoplasmology. Therefore, it is possible that drug-resistance might serve as a useful marker. We initially attempted to select drug-resistant acholeplasma in vitro using agar plates containing antibiotics. Consequently, it was found that EM-resistant mutants of acholeplasma arose at a rate of approximately $10^{-8}$. While some strains of acholeplasma showed even lower rates. Particularly, in the case of A. axanthum, an EM-resistant stain could not be obtained despite repeated trials using agar plates containing EM. The agar plate selection is considered to be one of the most convenient methods for the selection of drugresistant strains. However, because colonies of mycoplasma are very small, location by microscopic examination is necessary, thus considerably reducing the usefullness of this technique. In addition, the inoculum size is limited in the agar plate method. Our previous study showed that heavy inoculation inhibits the development of resistant colonies on the selection plate. Therefore, mutants which occur at extremely low frequencies can not be obtained by this method.

The following method reported in the present paper appears to overcome these disadvantages.

Fresh broth containing antibiotics was added to cultured medium with acholeplasma at the plateau phase of its growth. The plateau phase culture was used because drug-resistant acholeplasma mutants exist mostly at $10^{-8}$ or lower rates, thus the usage of a culture before plateau phase entails a risk that no resistant mutants are present in the culture. However, growth of resistant cells was not observed following addition of EM only to this culture (Fig. 1 Curve 3). Presumably, without the 
addition of a fresh energy source, the multiplication of resistant cells would be unlikely. Therefore, fresh broth containing EM was added to provide an energy source for the selective growth of resistant cells and to inhibit the sensitive cells. Growth of EM-resistant cells was observed in the case of the addition of fresh broth containing EM (selection and enrichment broth; SE-broth). On the contrary, such multiplication did not occurred in the controls, i. e., no addition, the addition of EM only and the addition of broth only (Fig. 1). Consequently, the effect of SE-broth on the growth of EM-resistant cells became clear. However, growth was relatively slow and required eleven days of cultivation to reach about $7.0 \log \mathrm{cfu} / \mathrm{ml}$.

The effect of the volume of SE-broth on the growth of resistant cells was examined. The addition of twice or thrice volumes of SE-broth to the cultured medium seemed to be sufficient for growth of resistant cells. The growth, however, was relatively slow when compared to that of isolated resistant strains, which usually reached approximately $9 \mathrm{log} \mathrm{cfu} / \mathrm{ml}$ at 3 days cultivation. Furthermore, growth of resistant cells was not obtained by the addition of an equal volume of SE-broth. Our speculation on this somewhat strange phenomenon was that killed, drug sensitive cells released a certain growth inhibitory substance into the mixed medium which suppressed the growth of resistant cells. To confirm this speculation, a cell-free filtrate was prepared from the $1: 1$ mixed culture after three days of cultivation. Growth inhibition of EM-resistant acholeplasma, reinoculated into the filtrate, was observed (Fig. 3). Further studies revealed that this inhibitory activity could be abolished by protease or trypsin at a final concentration of $10 \mathrm{mcg} / \mathrm{ml}$. These treatments had no effect on resistant cells. Therefore, we suspected that better growth of resistant cells might be obtained by the addition of protease to the SE-broth. As shown in Fig. 4, after the addition of SEbroth containing protease and erythromycin, the growth of resistant cells became rapid and the peak titer was higher than that of the control without protease. Accordingly, it could be concluded that the addition of protease improves the selective growth of resistant cells and that twice or thrice volumes of SE-broth should be added to the cultured medium. This selection method was tried with $A$. axanthum, because an EM-resistant strain could not be obtained by agar plate selection despite repeated trials. Since mutants of $A$. $a x$ anthum seemed to occur at extremely low frequency, a large volume of cultured medium was used. $90 \mathrm{ml}$ of SE-broth containing $\mathrm{EM}$ was added to $30 \mathrm{ml}$ of cultured medium. The result is shown in Fig. 5. The growth of resistant $A$. axanthum was prominent and reached approximately $8.0 \mathrm{log} \mathrm{cfu} / \mathrm{ml}$ by 5 days of cultivation. In this case the addition of protease was not necessary for good growth, presumably because a growth inhibitory substance released from killed sensitive cells is weak in this strain. Thus, it became clear that resistant mutants, existing at an extremely low frequency, could be enriched for by scaling up the system.

By the sequential application of this selection method using various drugs, it was possible to select a multiple drug-resistant of A. laidlawii. Also, this method was effective with acholeplasma species for the selection of drug-resistant strains.

Acknowledgment: This work was partially aided by the Grant from Research Project of the Ministry of Education.

\section{References}

Amikan, D., Razin.S. and Glaser, G. (1982). Ribosomal RNA genes in mycoplasma. Nucl. Acid. Res. 10, 4215-4222.

Koostra, W. L., Adams, J. N. and Smith, P.F. (1966). In vitro selection and identification 
of antibiotic-resistant mycoplasma mutants. J. Bacteriol. 91, 2386-2387.

Szybalski, W. and Bryson, V. (1952). Genetic studies on microbial cross resistance to toxic agents. J. Bacteriol. 64. 489-499.

Sмiтн P. F. (1956). Quantitative measurement of the growth of pleuropneumonia-like organisms. Appl. Microbiol. 4, 254. 